\title{
EXTERNAL FACTORS DETERMINING THE ELECTORAL STRATEGIES OF POLITICAL PARTIES IN MULTI-LEVEL SYSTEMS
}

\begin{abstract}
This article identifies the factors which determine the electoral strategies of political parties in multi-level systems and describes how they can influence these strategies. It particularly focuses on the two aspects: regionalisation and "nationalisation" (centralisation) of the strategies. In the first case, state-wide parties allow their regional branches to develop their own strategies, in the second one - the regional strategies are dominated by the strategies of statewide parties. The article shows the features of political systems that foster each of these cases, especially the way in which a multi-layered system is created (bottom-up, top-down), the relations between the state authorities at central and regional levels (connected, separated), electoral systems and cycles.
\end{abstract}

\section{Key words}

electoral strategies, political parties, multi-level system, party organisation, regionalisation

\section{Introduction}

Electoral strategies - together with programmatic, personal, promotional and coalitional - can be regarded as partial strategies, which make up the general strategies of political parties (Pawłowski, 2003, pp. 89-90). Therefore they can be considered as a concrete expression of the overall strategy, a way that serves the preparation and implementation of the policy offers that allow voters to

* Beata Kosowska-Gąstoł, Institute of Political Science and International Relations, Faculty of International and Political Studies, Jagiellonian University in Kraków, Poland, beata.kosowska-gastol@uj.edu.pl. 